\title{
GENDER INEQUALITIES IN MORBIDITY: A SOUTH AFRICAN INVESTIGATION
}

\author{
M. Ntuli ${ }^{a}$, M. Chitiga-Mabugu ${ }^{\text {b* }}$, S. Karuaihe ${ }^{c}$, F. Alabad, \\ N. Tsoanamatsie ${ }^{\mathrm{e}}$ and P. Kwenda ${ }^{\mathrm{f}}$
}

\begin{abstract}
International studies of gender differences in health status largely attest that women have worse health conditions than men, which compromise women's contribution to economic development. Using the South African Demographic and Health Survey of 2003, we investigate whether this disparity also holds in developing countries such as South Africa. Our results concur with previous findings that South African women are more likely to suffer from poor health than men. They also reveal that the health gap is largely driven by a relatively higher prevalence of health conditions among women, rather than by the severity of the conditions that they face. Furthermore, contrary to the common view that the health gap closes with age, we find that the gap exhibits little variation across age groups and it persists in old age. This suggests a need for preventive measures to reduce the occurrence of health conditions in South Africa - which is vital for economic development.
\end{abstract}

\section{Introduction}

One stylized fact of gender health inequalities is that women experience worse health conditions than men - gender health gap (Verbrugge, 1979, 1985, 1989; Nathanson, 1975, 1977). Current studies that include self-reported health, functional problems, disability, and health behaviours, suggest that gender disparities in health differ with age and health measure used, and are much smaller than suggested by earlier studies (Macintyre, Hunt \& Sweeting 1996, Lahelma \& Rahkonen, 1997; Arber \& Cooper, 1999, 2000; McDonough and Walters, 2001; Hunt, 2002; Gorman and Read, 2006; Crimmins, Kim, \& Sole'-Auro, 2010).

\footnotetext{
${ }^{* a}$ University of the Witwatersrand and Institute for the Study of Labor (IZA)

${ }^{\mathrm{b}}$ School of Public Management and Administration, University of Pretoria, Pretoria 0002, South Africa;

${ }^{c}$ Department of Agricultural Economics, Extension and Rural Development, University of Pretoria

${ }^{\mathrm{d}}$ Health Economics Unit, School of Public Health and Family Medicine, University of Cape Town

${ }^{\mathrm{e}} \mathrm{PhD}$ student, Economics Department, University of Pretoria

${ }^{\mathrm{f}}$ University of the Witwatersrand

Corresponding author email: margaret.chitiga@up.ac.za
} 
While the magnitude of the gender health gap is contentious, it is explicit that the gap triggers some socio-economic inequalities which deter economic development. These may manifest through relatively lower human capital development, labour force participation, productivity, and income among women (Bloom \& Canning, 2000; Wilkie \& Young, 2009). To some extent, this compromises women's contribution to sustainable economic development - women carry the triple burden of reproduction, market work (representing $40 \%$ of the global labour force, IMF, 2012), and household responsibilities. As such, the Millennium Development Goals (MDGs) place significant emphasis on reducing gender inequalities in health (MDG3), which are an epitome of broader gender inequalities in society.

In keeping with the global importance of health, several studies have explored health inequalities in South Africa. However, they were primarily concerned with the socioeconomic status health gradient and access to basic social services along the racial divide (Ataguba, 2011; Harling, Ehrlich \& Myer,2008; Doolan, Ehrlich \& Myer, 2007; Bradshaw \& Steyn, 2001; Zeida \& Lackan, 2008; Myer, Stein, Grimsrud, Seedat \& Williams, 2008; Harris, Goudge, Ataguba, McIntyre, Nxumalo, Jikwana \& Chersich, , 2011). Apart from descriptive analysis of gender differences in health outcomes provided by inter alia health survey reports such as the South African Demographic and Health Surveys (SADHS) of 1998 and 2003, little evidence based on comprehensive empirical work exists not only in South Africa (Hunt \& Annandale, 1999; Ardington \& Case, 2009).

Thus, given the dearth of literature within an African context, the objective of this study is to investigate whether women experience worse health conditions than men in South Africa. Using data from the 2003 Demographic and Health Survey for South Africa; we first explore whether there exists a gender gap in health, and whether it varies by age and type of health condition. Second, we examine the sources underlying the gender health gap using an Oaxaca-Blinder (1973) type decomposition technique for binary dependent variables, as used by Case and Paxson (2005). This partitions the gender differential in health outcomes into three components: (i) prevalence effect, (ii) severity effect and; (iii) a residual. This analysis helps us to understand if the gender gap is due to gender differences in prevalence of health conditions or in health severity.

In terms of the paper outline, Section 2 provides a brief review of the related literature and South Africa's background, followed by Section 3 on the methodology and the data used in the analysis. Section 4 discusses the results in the model and some robustness checks and Section 5 provides a concluding discussion. 


\section{$2 \quad$ Literature review and background}

\subsection{Gender disparities in health}

Studies that examine gender disparities in health have consistently found higher rates of morbidity among women than men (Nathanson 1977; Verbrugge 1979, 1985). However, the type of health conditions experienced by women and men vary significantly (Guralnik, Andrea, LaCroix, Everett \& Kovar, 1989). Women have been found to have higher rates of illness in non-fatal health conditions such as headaches or arthritis (Lubitz, Cai, Kramarow \& Lentzner, 2003; Case and Paxson, 2005; 2003; Merrill, Seeman, Kasl, \& Berkman, 1997) while men suffer more from life threatening chronic diseases such as cardio-vascular diseases (Verbrugge, 1989; Gorman \& Read, 2006). These differences in types of conditions faced by men as opposed to women partly explain why women are more likely to rate themselves in poor health than men - the conditions faced by women are more likely to occur frequently and to many people than those of men.

Several explanations for these differences have been provided in the literature. First, the distributions of health conditions vary by gender perhaps due to biological and behavioural factors (Case \& Paxson, 2005; Molarius \& Janson, 2002). Second, gender differences with regards to occupational hazards and health habits have also been cited as causal factors (Verbrugge, 1989). Third, other studies maintain that the gender health inequality varies by age; some studies have found that gender disparities in health become smaller with age or even disappear in old age (Arber \& Cooper, 2000; Case \& Deaton, 2003; Leinonen, Heikkinen \& Jylha, 1997; Macintyre et al., 1996). Given that age is an important determinant of the gender health gap, the importance of conducting studies by age has been emphasised by recent studies (Arber \& Cooper, 1999; Case \& Paxson, 2005).

\subsection{South African context}

South Africa's transition from political apartheid to a democratic regime has seen dramatic changes in its socio-economic environment. In the apartheid era, virtually all systems in the economy such as employment, education and access to health services were defined on the basis of race and gender. Such a system can be argued to have disproportionately exposed the African majority to higher risks of morbidity with women being affected significantly more than men as they suffered both racial and gender discrimination (Scully, 1995).

The transition to a democratic government was accompanied by a constitutional requirement to redress the detrimental effects of apartheid. The fragmented health service system was consolidated and a publicly funded health system was instituted which serves most South Africans (The Lancet, 2009; Zeida \& Lackan, 2008). To date, successful health programmes have been implemented from centrally regulated approaches such as tobacco control, food fortification, drug pricing, among others 
(The Lancet, 2009). Despite these efforts, South Africa is currently battling with the burden of both communicable (CDs) and non-communicable diseases (NCDs) ${ }^{2}$ alongside HIV/AIDS. According to Econex (2009), South Africa's burden of disease is on average four times larger than that of developed countries and in most instances, it almost doubles that of developing countries. This can be better understood by comparing South Africa's situation against other comparable countries. Table 1 shows South Africa's position relative to 14 other countries, selected and ordered by income per capita for 2010 (Institute for Health Metrics and Evaluation (IHME), 2013). Position 1 indicates best rank and 15 indicates worst rank. Table 1 shows that South Africa is at the top rung (rank 15) of the burden of disease using four indicators: (i) Age-standardised death rate per 100000 population; (ii) Agestandardised years of life lost (YLLs) per 100000 population, i.e. premature deaths due to burden of disease; (iii) Life expectancy at birth (LE); and (iv) Health adjusted life expectancy at birth (HALE). South Africa's position is even worse than the country with the lowest income per capita, the Dominican Republic. For instance, South Africa has a death rate of 1266 per 100000 population compared to 683 for Dominican Republic, and 462 for the best ranked country, Costa Rica. What is interesting is that countries like Costa-Rica, Cuba, Panama, and Serbia have better health rankings than the relatively advanced/industrialised countries like Brazil and South Africa. This shows a misalignment between income level and resource allocations towards health services, or there could be other underlying factors.

Table 1: Country benchmarking of burden of disease, 2010

\begin{tabular}{|c|c|c|c|c|c|c|c|c|}
\hline \multirow[b]{2}{*}{ Country } & \multicolumn{2}{|c|}{$\begin{array}{l}\text { Age-standardized } \\
\text { death rate } \\
(\text { per } 100,000)\end{array}$} & \multicolumn{2}{|c|}{$\begin{array}{l}\text { Age-standardized } \\
\text { YLL rate } \\
\text { (per 100,000) }\end{array}$} & \multicolumn{2}{|c|}{$\begin{array}{l}\text { Life expectancy } \\
\text { at birth (LE) }\end{array}$} & \multicolumn{2}{|c|}{$\begin{array}{l}\text { Health adjusted } \\
\text { Life expectancy at } \\
\text { birth (HALE) }\end{array}$} \\
\hline & Rate & Rank & Rate & Rank & LE & Rank & HALE & Rank \\
\hline Kazakhstan & 1043 & 14 & 29881 & 14 & 66.7 & 14 & 58.2 & 14 \\
\hline Costa Rica & 462 & 1 & 10447 & 1 & 79.4 & 1 & 68.9 & 1 \\
\hline Romania & 712 & 12 & 16325 & 7 & 73.8 & 10 & 64.4 & 7 \\
\hline Panama & 545 & 3 & 14027 & 6 & 76.7 & 4 & 66.5 & 2 \\
\hline Iran & 640 & 7 & 16780 & 9 & 74.4 & 8 & 63.2 & 9 \\
\hline Brazil & 670 & 8 & 17580 & 10 & 74.1 & 9 & 63.8 & 8 \\
\hline Serbia & 572 & 4 & 12077 & 3 & 76.7 & 3 & 66 & 3 \\
\hline South Africa & 1266 & 15 & 48286 & 15 & 59.9 & 15 & 51 & 15 \\
\hline Cuba & 543 & 2 & 11088 & 2 & 77.9 & 2 & 65.2 & 4 \\
\hline Montenegro & 637 & 6 & 13549 & 4 & 75.6 & 5 & 64.7 & 6 \\
\hline Suriname & 693 & 11 & 20892 & 13 & 72.6 & 12 & 60.7 & 12 \\
\hline Jamaica & 610 & 5 & 16417 & 8 & 75.3 & 6 & 62.8 & 10 \\
\hline Macedonia & 682 & 9 & 13939 & 5 & 75 & 7 & 64.8 & 5 \\
\hline $\begin{array}{l}\text { Saint Vincent \& the } \\
\text { Grenadines }\end{array}$ & 753 & 13 & 20602 & 12 & 72 & 13 & 60.2 & 13 \\
\hline $\begin{array}{l}\text { Dominican } \\
\text { Republic }\end{array}$ & 683 & 10 & 18385 & 11 & 73.7 & 11 & 62.2 & 11 \\
\hline
\end{tabular}

Source: Institute for Health Metrics and Evaluation, 2013

2 Communicable diseases are infectious diseases like HIV/AIDS, cholera and influenza while noncommunicable diseases are non-infectious diseases such as cardiovascular diseases, diabetes and cancers. 
Further, the 2010 Global Burden of Disease (GBD) study identified the top ten causes of premature death related to YLLs in South Africa and Table 2 shows the YLLs from these diseases as found by the GBD study (IHME, 2013).

Table 2: Top 10 causes of YLLs in South Africa, 2010

\begin{tabular}{l|l|c|c}
\hline Rank & Disease & $\begin{array}{l}\text { Number of YLLs } \\
\text { in thousands }\end{array}$ & Percentage of total YLLs \\
\hline 1 & HIV/AIDS & 11201 & 47.9 \\
\hline 2 & Diarrheal diseases & 1138 & 4.9 \\
\hline 3 & Interpersonal violence & 1018 & 4.4 \\
\hline 4 & Lower respiratory infections & 873 & 3.7 \\
\hline 5 & Tuberculosis & 760 & 3.3 \\
\hline 6 & Stroke & 543 & 2.3 \\
\hline 7 & Preterm birth complications & 500 & 2.1 \\
\hline 8 & Diabetes mellitus & 489 & 2.1 \\
\hline 9 & Mechanical forces & 393 & 1.7 \\
\hline 10 & Ischemic heart diseases & 383 & 1.6 \\
\hline
\end{tabular}

Source: Institute for Health Metrics and Evaluation, 2013

While the overall burden of disease in South Africa is known, more remains to be understood with regards to the extent of the health gap between men and women. Figure 1 show YLLs for South African men and women for 2000 - the latest year for which data is available.

Males

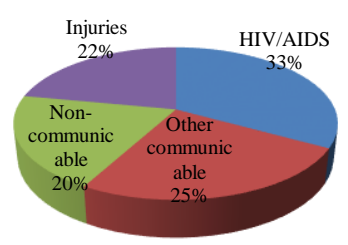

\section{Females}

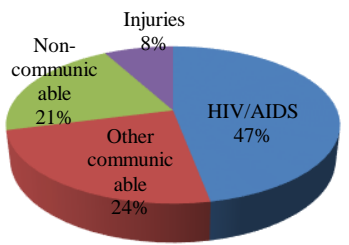

Figure 1: Years of life lost (YLL) by sex, 2000

Source: Bradshaw, Groenewald, Laubscher, Nannan, Nojilana Norman, Desiréé \& Schneider (2003)

Although there is no considerable difference between men and women with regards to other CDs and NCDs, it is clear for HIV/AIDS and injuries that the burden of 
disease differs between the sexes. Currently, the government has proposed a series of reforms to improve the health care delivery system. This includes the introduction of the National Health Insurance (NHI) scheme aimed at providing health care coverage to all South Africans (Department of Health (DoH), 2011). In addition to the NHI scheme, there is an initiative by the DoH to 're-engineer' the Primary Health Care (PHC) system (DoH, 2010). This is aimed at strengthening the district health system (DHS), promoting the delivery of community-based services with an emphasis on preventative rather than the curative measures which currently dominates the menu of health care services (Schaay, Sanders, Kruger \& Olver, et 2011).

\section{$3 \quad$ Methodology}

The paper uses a two stage estimation procedure. The first stage investigates whether women have worse self-reported health status than men, the second analyses sources of the gender inequality in health following the decomposition procedure by Case and Paxson (2005).

Stage 1: To investigate whether there is a gender differential in health status we estimate the following probit model

$$
\hat{H}_{i}=\sum_{i=1}^{n} \Phi\left(\mathbf{D}_{i} \hat{\Psi}+\mathbf{X}_{i} \hat{\beta}+F_{i} \hat{\gamma}\right)
$$

where $\hat{H}$ is an estimate of individual $i$ 's health status - two measures of health status are considered in the study. In the survey, individuals are requested to rate whether their health status is poor, fair, good, very good or excellent. Based on this information, we construct the first measure of health, that is, self-rated health (SRH) which takes the value of 1 if an individual rates his/her health as poor/fair, and 0 if health is rated as good, very good or excellent. Previous studies suggest that men and women have different health reporting behaviours with men being more stoical than women (Case \& Paxson, 2005; Spiers, Jagger, Clarke \& Arthur, 2003). Consequently, the use of SRH as the only measure of health might give misleading results if health differences between men and women are purely driven by a reporting bias. To address this potential limitation of SRH, we also use health service utilisation (HSU) as an alternative measure of health status. This is also a binary indicator taking the value of 1 if an individual utilised any health care services in the past month or 0 otherwise. Arguably, HSU provides a more objective measure of health relative to SRH as it is not subject to an individual's perception and assessment of their health status.

$D_{i}$ is a vector of selected self-reported health conditions (osteoporosis, arthritis, epilepsy, tuberculosis, asthma, bronchitis/emphysema, diabetes, blood pressure, 
heart attack, stroke, cholesterol, and toothache) for individual $i ; x$ is a vector of individual $i$ 's observable characteristics (age, education, household size, geographic location, asset index, drinking and smoking habits, nutrition, exposure to violence, and whether individual $i$ participates in physical exercises). $\mathrm{F}$ is a gender dummy: 1 if female and 0 otherwise. $\widehat{\Psi}, \widehat{\beta}$ and $y$ are the estimated probit coefficients for health conditions, individual characteristics and the gender dummy, respectively; $\Phi$ is the standard normal cumulative density function. Generally, the coefficients of the probit model are difficult to interpret directly. Consequently, we compute and present marginal effects which measure changes in the conditional probability associated with changes in a given covariate. In our model, $\hat{y}$ is the coefficient of interest. We interpret the corresponding marginal effect as the gender differential in self-reported health status - if it is positive it implies women are more likely to be in poor health than men, and vice versa.

Stage 2: To investigate the underlying causes of the gender health gap, this study applies the Oaxaca-Blinder (1973) type decomposition for binary dependent variables as shown by Case and Paxson (2005) when $\hat{y}$ in equation (1) is statistically significant. The decomposition analysis indicates the significant predictors of the gap, and partitions their effects into differences in sample means (characteristic effect) and differences in coefficients, and a residual. In the case of health conditions, the first component is attributed to differences in distribution of health conditions while the second is ascribed to the severity of these conditions, effects of other observable and unobservable predictors are captured by the residual. This partitioning enables us to make more specific conclusions on the impact of health conditions on health status, than if we only had aggregate effects of the predictors.

While we are aware of other decomposition techniques for non-linear functions such as Even and Macpherson (1990 1993), Fairlie (2005) and Yun (2004), we have utilised the approach by Case and Paxson (2005) for a number of reasons. First, the method puts emphasis on the effect of health conditions on self-reported health, which is of our main interest. Second, Even and Macpherson $(1990 ; 1993)$ and Fairlie (2005) only show the contribution of significant correlates to the characteristic effect, but not the coefficient effect. Hence they do not allow us to dissect the effect of health conditions into prevalence and severity effects. This caveat is, however, addressed by Yun (2004) who further solved the invariance problem that the contribution of dummy variables to the coefficient effect is sensitive to the choice of the base category. However, in our case the health conditions are not coded as a single outcome with different categories, hence they are not affected by the invariance problem.

The Case and Paxson (2005) procedure entails firstly estimating a probit model of self-rated health $(\hat{H})$ for each sex $j \in\{$ women, men $\}$ i.e.: 
$\hat{H}_{j}=\sum_{i=1}^{n_{J}} \Phi\left(\mathbf{D}_{i j} \hat{\Psi}_{j}+\mathbf{X}_{i j} \hat{\beta}_{j}\right)$

where the variables and the parameters are as previously defined.

The findings from equation (2) are used to predict the probability of self-rated health for every individual $i$ in the sample $\left(\widehat{H}_{i j}\right)$. Thereafter, these predicted probabilities are averaged to give the proportion of individuals of $\operatorname{sex} j$ who self-rated themselves in poor/fair health $\overline{\hat{H}}_{j}$. Case and Paxson (2005) suggest that the difference in men's and women's average predicted probabilities of poor/fair health (Hgap) can be largely explained by differences in the distribution of health conditions across gender. To examine this, the gender health gap is then decomposed into three components as follows:

$\underbrace{\overline{\hat{H}_{w}}-\overline{\hat{H}}}_{\text {Hgap }}=\underbrace{\sum_{i}\left(\overline{D_{i w}}-\overline{D_{i m}}\right) \overline{\hat{\Psi}}_{i}}_{\text {prevalence effect }}+\underbrace{\sum_{i}\left(\hat{\Psi}_{i w}-\hat{\Psi}_{i m}\right) \overline{D_{i}}}_{\text {severity effect }}+$ Residualeffect

where $\bar{D}_{i}$ and $\overline{\hat{\Psi}}_{\mathrm{i}}$ denote an average over men and women's occurrence rates of each condition, and the average over their coefficients of each condition, respectively. The prevalence effect gives the proportion of Hgap that is explained by gender differences in occurrence of conditions, weighted by $\overline{\hat{\Psi}}_{\mathrm{i}}$. The severity effect measures the component of Hgap that is ascribed to differences in seriousness of the conditions experienced by men and women. It is given by differences in the conditions' coefficients, weighted by $\bar{D}_{i}$. The residual effect captures a component of Hgap that is explained by coefficients and distributions of other explanatory variables as well as unobserved characteristics that influence the probability of being in poor/fair health.

\section{$4 \quad$ Data and findings}

\subsection{Data}

The data utilised for the study were drawn from the adult module of the South African Demographic and Health Survey (SADHS) for $2003^{3}$. The 2003 SADHS is the

\footnotetext{
${ }^{3}$ While we are aware that the two waves of National Income Dynamics Study (NIDS) data for 2008 and 2011 have a health module, these datasets are not as comprehensive as the SADHS whose sole purpose is to collect information on health. Moreover, our analysis of the first wave of NIDS showed an unconditional gender health
} 
second nationally representative health survey produced by the Department of Health; the first was produced in 1998. The survey is instrumental for evaluating the coverage and outcomes of government's health programmes. The 2003 data contains information on individuals residing in 7756 households across the country. The adult health module has extensive questions about health conditions, health service utilisation, and health behaviours of 8815 individuals aged between 15 and 93 years. For the purpose of this study only individuals aged between 15 and 75 years were considered (this allows us a reasonable sample for comparison) provided they had information on self-rated health status. This leaves a final sample composed of 3251 men and 4642 women.

As discussed earlier, to determine gender differentials in health, we use self-rated health status (SRH) and health service utilisation (HSU) as measures of health. We have noted that SRH might potentially be limited due to reporting bias - traditionally women are more likely to factor in regular non-serious ailments in their assessment of health compared to men, hence, the disadvantage of women uncovered in the analysis might partly be reflective of this. The data also presents self-reported information on chronic conditions which we categorised into three main categories i.e. severe pain (osteoporosis, arthritis, epilepsy), respiratory conditions (tuberculosis, asthma, bronchitis/emphysema), and circulatory conditions (diabetes, blood pressure, heart attack, stroke, and cholesterol). We also have information on weight indicators and toothache. In the analysis, toothache is used as a proxy for minor diseases. Health risk behaviours utilised include lack of exercise, smoking, drinking and risky nutrition. Regrettably, our data does not have information on HIV/AIDs which is one of the main 'killer' diseases in South Africa and disproportionately affects women's lives in terms of infection rate (Peacock \& Levack, 2004 \& Shisana, Rihele, Simbayi, Zuma, Jooster, Zungu, Labadarios \& Onoya, 2014). However, a recent study indicates a decline in HIV mortality among women compared to men (Bor, Rosen, Chimbindi, Haber, Herbst, Mutevedzi, Tanper, Pillay \& Bärnighausen, 2015). For this study however, our analysis is limited to the health conditions that are contained in the dataset at use. In view of this, future studies may benefit from including this health condition should the data be available.

Socio-economic and demographic data include area of residence (urban/rural), provincial dummies, household size, education, race and asset index- derived using a Principal Components Analysis of the assets owned by an individual's household. The list of assets includes a radio, a television, a computer, a refrigerator, telephone/cellphone, a bicycle, a car, a donkey or cattle. A description of the variables used in the model is presented in Table A.1 in the Appendix. The descriptive statistics i.e. means/proportions and standard errors are presented in Table 3.

gap of $6.7 \%$ points for $15-75$ year olds. The gap vanished after controlling for observable characteristics, which is suspicious given the country's health profile. 
Table 3: Descriptive statistics

\begin{tabular}{|c|c|c|c|c|c|}
\hline \multirow[b]{2}{*}{ Variable } & \multicolumn{2}{|l|}{ Female } & \multicolumn{2}{|l|}{ Male } & \multirow[b]{2}{*}{$\begin{array}{l}\text { Female - Male } \\
\text { Diff in Means }\end{array}$} \\
\hline & $\begin{array}{l}\text { Mean/ } \\
\text { Prop }\end{array}$ & $\begin{array}{r}\text { Std. } \\
\text { Error }\end{array}$ & $\begin{array}{l}\text { Mean/ } \\
\text { Prop }\end{array}$ & $\begin{array}{r}\text { Std. } \\
\text { Error }\end{array}$ & \\
\hline SRH & 0.628 & 0.007 & 0.546 & 0.009 & $0.082 * * *$ \\
\hline HSU & 0.402 & 0.007 & 0.293 & 0.008 & 0.109 *** \\
\hline Age & 37.438 & 0.234 & 35.168 & 0.280 & $2.270 * * *$ \\
\hline Household size & 4.802 & 0.037 & 4.618 & 0.047 & 0.184 *** \\
\hline Urban & 0.566 & 0.007 & 0.589 & 0.009 & $-0.023 * * *$ \\
\hline Asset index & 0.188 & 0.011 & 0.184 & 0.013 & 0.003 \\
\hline Underweight & 0.064 & 0.004 & 0.139 & 0.006 & $-0.074 * * *$ \\
\hline Healthy weight & 0.390 & 0.007 & 0.561 & 0.009 & $-0.171 * * *$ \\
\hline Overweight & 0.316 & 0.007 & 0.258 & 0.008 & $0.058 * * *$ \\
\hline Obese & 0.288 & 0.007 & 0.109 & 0.005 & $0.179 * * *$ \\
\hline \multicolumn{6}{|l|}{ Circulatory conditions } \\
\hline Blood pressure & 0.191 & 0.006 & 0.092 & 0.005 & $0.099 * * *$ \\
\hline Heart attack & 0.046 & 0.003 & 0.033 & 0.003 & 0.013 *** \\
\hline stroke & 0.011 & 0.002 & 0.011 & 0.002 & 0.000 \\
\hline cholesterol & 0.023 & 0.002 & 0.022 & 0.003 & 0.001 \\
\hline diabetes & 0.042 & 0.003 & 0.031 & 0.003 & $0.011 * * *$ \\
\hline Aggregated & 0.232 & 0.006 & 0.139 & 0.006 & $0.093 * * *$ \\
\hline \multicolumn{6}{|l|}{ Respiratory Conditions } \\
\hline Bronchitis & 0.026 & 0.002 & 0.020 & 0.002 & $0.006^{* *}$ \\
\hline Asthma & 0.042 & 0.003 & 0.031 & 0.003 & $0.011 * * *$ \\
\hline Tuberculosis & 0.021 & 0.002 & 0.031 & 0.003 & $-0.010 * * *$ \\
\hline Aggregated & 0.078 & 0.004 & 0.071 & 0.005 & 0.007 \\
\hline \multicolumn{6}{|l|}{ Pain related conditions } \\
\hline Osteoporosis & 0.023 & 0.002 & 0.015 & 0.002 & $0.009 * * *$ \\
\hline Epilepsy & 0.015 & 0.002 & 0.013 & 0.002 & 0.002 \\
\hline Arthritis & 0.080 & 0.004 & 0.049 & 0.004 & 0.030 *** \\
\hline Aggregated & 0.103 & 0.004 & 0.068 & 0.004 & $0.035 * * *$ \\
\hline Toothache & 0.190 & 0.006 & 0.173 & 0.007 & $0.017 * *$ \\
\hline \multicolumn{6}{|l|}{ Health related habits } \\
\hline Violence & 0.031 & 0.003 & 0.053 & 0.004 & $-0.022 * * *$ \\
\hline Exercise & 0.227 & 0.006 & 0.356 & 0.008 & $-0.129 * * *$ \\
\hline Smoker & 0.120 & 0.005 & 0.379 & 0.009 & $-0.259 * * *$ \\
\hline Drinker & 0.116 & 0.005 & 0.321 & 0.008 & $-0.205^{* * *} *$ \\
\hline Risky Nutrition & 0.236 & 0.006 & 0.256 & 0.008 & $-0.020 * *$ \\
\hline \multicolumn{6}{|l|}{ Education } \\
\hline No schooling & 0.129 & 0.005 & 0.094 & 0.005 & $0.036^{* * * *}$ \\
\hline Primary & 0.224 & 0.006 & 0.232 & 0.007 & -0.008 \\
\hline Incomplete Secondary & 0.394 & 0.007 & 0.404 & 0.009 & -0.010 \\
\hline Matric & 0.198 & 0.006 & 0.207 & 0.007 & -0.009 \\
\hline Post-secondary & 0.051 & 0.003 & 0.057 & 0.004 & -0.005 \\
\hline \multicolumn{6}{|l|}{ Race } \\
\hline African & 0.738 & 0.006 & 0.764 & 0.007 & $-0.026 * * *$ \\
\hline Coloured & 0.135 & 0.005 & 0.107 & 0.005 & $0.028 * * *$ \\
\hline White & 0.089 & 0.004 & 0.091 & 0.005 & -0.002 \\
\hline Indian & 0.037 & 0.003 & 0.036 & 0.003 & 0.001 \\
\hline Provinces & Yes & Yes & Yes & Yes & \\
\hline $\mathrm{N}$ & 4642 & & 3251 & & \\
\hline
\end{tabular}


We also carried out a graphical analysis of the gender health gap by age, based on Cleveland's (1979) non-parametric locally weighted scatter plot smoothing (lowess) technique. Lowess does not impose a functional form on the data, instead it allows the data to determine estimates of the parameters and shapes of the curves. The technique carries out a locally weighted regression of a health condition for men/women as a function of age, and displays the graph. In this case we specified a constant bandwidth of 0.3 , implying that $30 \%$ of the sample was used to smooth each point. The created scatters of points are presented in Figures 2-5. All statistical analysis was carried out using the STATA software, version 12 (Stata Corp. Inc., TX, USA).

Table 3 reveals that on average women are older than men, which suggests that women live longer than men. Women report worse self-rated health than men; on average $62.8 \%$ of women and $54.6 \%$ of men reported poor/fair health. This gender gap is, however, unevenly distributed across the individuals' age distribution. Figure 2 , depicting the proportions of men and women who reported poor/fair health by age, shows that the gap widens between the age group 25-40. The disadvantaged position of women in this age-cohort could be partly due to their reproductive stage of the life-cycle which exposes them to risks associated with childbirth (Yin, 2007). Also attesting the relatively poor health status of women is that they are significantly more likely to utilise health care services (HSU) than men (40.2\% vs. $29.3 \%$ ).

The gender differential is, however, not uniformly distributed across the age distribution, actually it increases with age, see Figure 2 . These results are contrary to previous findings from developed countries (c.f. Arber \& Cooper, 1999; Case \& Paxson, 2005) which suggest that the health gap decreases with age. The results show that South African women are consistently disadvantaged throughout their lifetime. This is partly attributable to women's low decision making power in third world countries, such that definitions of health status and access to and utilisation of modern healthcare all reflect the subordinate social status of women (Okojie, 1994). 


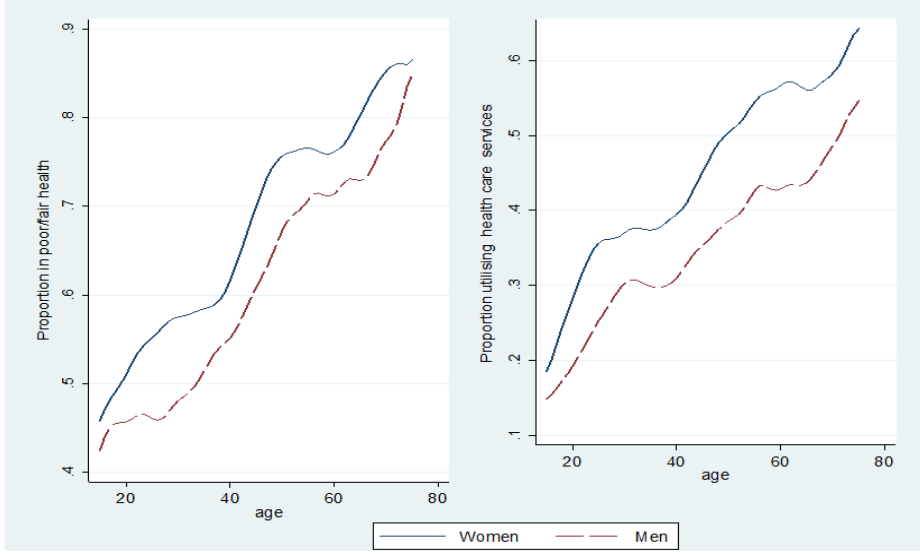

Figure 2: Self-rated health and health care utilisation by gender and age

Concerning health conditions, the statistics suggest that women are more likely to experience pain (i.e. osteoporosis, arthritis, epilepsy, etc.) than men i.e. 10.3\% of women and $6.8 \%$ of men. This outcome extends to toothache which affected $19 \%$ of women and $17.3 \%$ of men, respectively. Figure 3 shows that the ratio of men and women who suffered from pain is similar at ages below 40, and increases thereafter with women's outpacing men's. This result is mainly driven by distributions of osteoporosis and arthritis as presented in Figure 3.
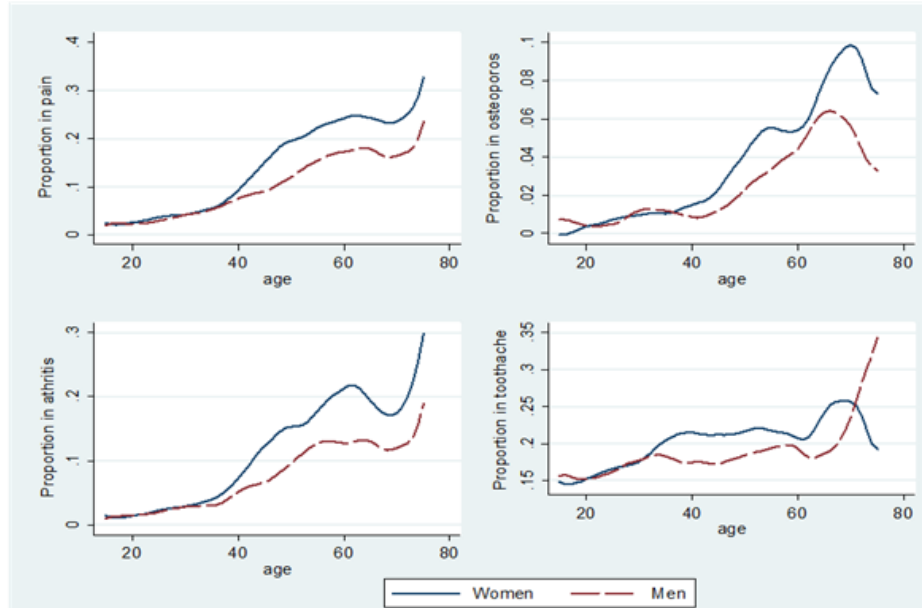

Figure 3: Pain-related health conditions by gender and age 
Furthermore, when aggregated, the occurrence of respiratory conditions (tuberculosis, asthma, bronchitis, emphysema, etc.) is statistically similar for men and women. This is supported by the first panel of figure 4 which shows that neither distribution monotonically dominates the other. However, men are significantly more likely to suffer from tuberculosis than women. The male dominance in prevalence of tuberculosis increases with age and peaks around 55 years (see figure 4). A similar observation was made by the World Health Organization (WHO) in their study of Gender and Tuberculosis (WHO, 2003). On the contrary, more women suffer from asthma $-4.2 \%$ vs. $3.1 \%$; the prevalence rates increase with age as shown in figure 4 . Figure 4 further demonstrates that women experience a marginally higher occurrence of bronchitis than men, except for those aged between 50 and 60 . On the basis of respiratory conditions, it can be argued that women suffer from non-fatal conditions than men and are therefore healthier since tuberculosis is one of the top ten causes of YLLs in South Africa (see Table 2) while asthma and bronchitis are not major causes of premature death in South Africa.

With regards to circulatory conditions we find that women are more likely to suffer from these conditions than men, see Figure 5. The high prevalence of circulatory conditions among women is mainly driven by high blood pressure and obesity which consistently affect more women across the life-cycle. The findings for obesity are in line with the fact that men are more physically active than women (Yin, 2007). The result for high blood pressure is inconsistent with findings from developed countries, which suggest that before age 45 , a higher proportion of men than women suffer from high blood pressure but during midlife women start overtaking the proportion of men (Tischler, 2013). This could be partly due to the fact that women in developing countries disproportionately suffer from the triple burden of reproduction, household responsibilities, and socio-economic related work.

With regards to heart attack and diabetes, we find that there are no clear dominant patterns in the early stages; however, these diseases are more prevalent among women starting at 45 years. The result on heart disease is somewhat contrary to the findings from previous studies (e.g. Jevon, 2012), which suggest that the incidence of heart attack is more prevalent among men than women. While risk factors for heart disease such as; smoking and drinking are higher among men than women, the high levels of obesity and inactivity among women can be potential reasons for the high prevalence of heart disease among South African women. 

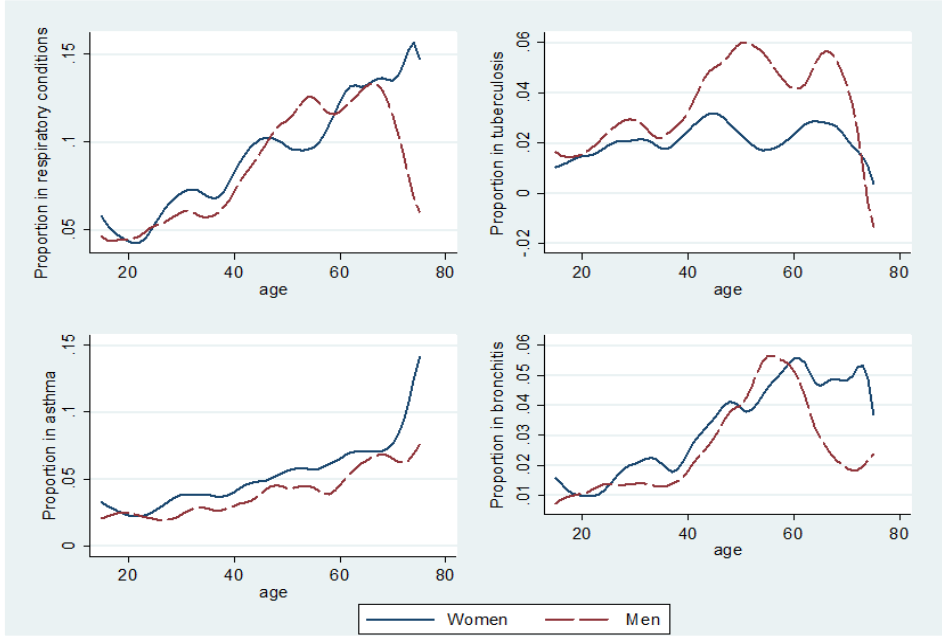

Figure 4: Respiratory conditions by gender and age

As for health-related risk behaviour (drinking, lack of exercises, smoking, violence, and nutrition), men are significantly more likely to engage in excessive drinking, smoking, physical violence, and risky nutrition habits than women. These habits are, therefore, anticipated to have more adverse effects on men's health when compared to women. Similarly the proportion of men who participated in physical exercises is greater than women's (35.3\% vs. $22.5 \%)$. Hence we expect this variable to positively influence men's health more than it does for women.

Concerning proxies for socio-economic status: education and asset ownership, while the proportion of women without schooling is statistically larger than that of men (12.9\% vs. 9.4\%), their proportions in other levels of education (i.e. primary, incomplete secondary, complete secondary, and post-secondary) are statistically similar. The largest share of both genders has primary and incomplete secondary education; only about $5 \%$ of both genders have post-secondary education. Further, the averages for indices of asset ownership are statistically similar for men and women. It is also notable that Africans dominate our samples (about 75\%) followed by Coloureds, Whites and Indians, respectively. The next section discusses findings of the regression models presented in equations (1) and (2) respectively. 

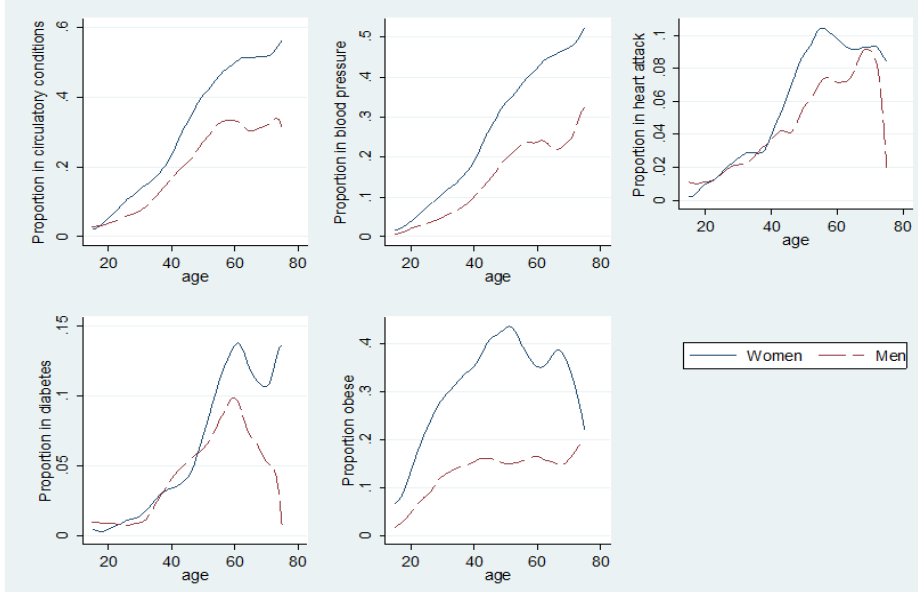

Figure 5: Circulatory conditions by gender and age

\subsection{Findings}

\section{Covariates of the health status}

Table 4 presents results i.e. marginal effects (MFX) and standard errors for probit models of SRH. The marginal effects are computed at the mean of the continuous covariates. For the dummy variables the marginal effect is a change in the probability of being in poor health due to a discrete change of a dummy variable from 0 to 1 . Column I gives estimates for equation 1 (pooled regression of men and women), while columns II and III presents estimates for equation (2) (separate models by gender).

The findings reveal that women are more likely to experience poor/fair health than men. The probability of being in poor health increases with age relative to the base category of 15-24 years. This is expected given that health typically deteriorates over the lifecycle. Contrary to the findings of Arber and Cooper (1999) and Case and Paxson (2005) we find the gender health gap does not close with age. The persistency of the gap in SRH in old age may be due to the distribution of health conditions women are more likely to suffer from asthma, pain related conditions (arthritis and osteoporosis), diabetes and high blood pressure in old age than men. The health gap persists in old age for these health conditions; however, there are some conditions for which the health gap narrows with age i.e. tuberculosis, bronchitis and obesity.

With regards to health conditions, circulatory conditions are positively correlated with self-rating in poor health. For instance, blood pressure increases the probability for men and women by $16.3 \%$ and $11.5 \%$, respectively. However, there is no 
statistical difference in the effect of circulatory conditions on men and women's selfrated health conditions. Results for respiratory conditions reveal that asthma and bronchitis commonly increase the propensities of being in poor health; asthma has a relatively large effect than bronchitis. The impact of tuberculosis is only positive and statistically significant for women, it is insignificant for men. The tuberculosis result for men could have been affected by controls for smoking.

Table 4: Results for probit models of self-rated health (SRH) by gender

\begin{tabular}{|c|c|c|c|c|c|c|}
\hline \multirow[b]{3}{*}{ Variable } & \multicolumn{2}{|c|}{ (I) } & \multicolumn{2}{|c|}{ (II) } & \multicolumn{2}{|c|}{ (III) } \\
\hline & \multicolumn{2}{|l|}{ Full model } & \multicolumn{2}{|l|}{ Women } & \multicolumn{2}{|l|}{ Men } \\
\hline & MFX & Std. Err. & MFX & Std. Err. & MFX & Std. Err. \\
\hline Female & $0.090 * * *$ & 0.013 & - & - & - & - \\
\hline $25-34$ years & $0.063 * * *$ & 0.016 & $0.073 * * *$ & 0.021 & 0.040 & 0.027 \\
\hline $35-44$ years & $0.080 * * *$ & 0.018 & $0.080 * * *$ & 0.022 & $0.069 * * *$ & 0.029 \\
\hline $45-54$ years & $0.178 * * *$ & 0.018 & $0.177 * * *$ & 0.022 & $0.178 * * *$ & 0.030 \\
\hline 55-64 years & $0.158 * * *$ & 0.022 & $0.150 * * *$ & 0.027 & $0.164 * * *$ & 0.036 \\
\hline $65+$ years & $0.230 * * *$ & 0.023 & $0.210 * * *$ & 0.028 & $0.255 * * *$ & 0.038 \\
\hline Blood Pressure & $0.130 * * *$ & 0.018 & $0.115 * * *$ & 0.021 & $0.163 * * *$ & 0.035 \\
\hline Heart attack & $0.132 * * *$ & 0.034 & $0.091 * *$ & 0.042 & $0.201 * * *$ & 0.058 \\
\hline Stroke & $0.178 * * *$ & 0.058 & $0.155 * * *$ & 0.075 & $0.223 * *$ & 0.090 \\
\hline Cholesterol & 0.046 & 0.046 & 0.053 & 0.057 & 0.034 & 0.075 \\
\hline Diabetes & $0.142 * * *$ & 0.033 & $0.156 * * *$ & 0.038 & $0.112 *$ & 0.060 \\
\hline Bronchitis & $0.131 * * *$ & 0.041 & $0.134 * * *$ & 0.048 & $0.129 *$ & 0.074 \\
\hline Asthma & $0.174 * * *$ & 0.030 & $0.192 * * *$ & 0.032 & $0.147 * *$ & 0.057 \\
\hline Arthritis & $0.138 * * *$ & 0.026 & $0.109 * * *$ & 0.031 & $0.202 * * *$ & 0.045 \\
\hline Osteoporosis & $0.122 * *$ & 0.050 & $0.155 * * *$ & 0.053 & 0.043 & 0.100 \\
\hline Epilepsy & $0.106^{* *} *$ & 0.052 & 0.046 & 0.069 & $0.171 * *$ & 0.081 \\
\hline Tuberculosis & $0.094 * *$ & 0.039 & $0.192 * * *$ & 0.045 & 0.004 & 0.060 \\
\hline Toothache & 0.016 & 0.016 & $0.038 *$ & 0.020 & -0.020 & 0.026 \\
\hline Violence & $0.064 * *$ & 0.030 & 0.056 & 0.043 & 0.062 & 0.043 \\
\hline Exercises & $-0.058 * * *$ & 0.014 & $-0.036^{*}$ & 0.020 & $-0.069 * * *$ & 0.021 \\
\hline Smoker & $0.040 * *$ & 0.016 & 0.035 & 0.027 & $0.058 * * *$ & 0.022 \\
\hline Drinker & $0.058 * * *$ & 0.016 & $0.046 *$ & 0.025 & $0.069 * * *$ & 0.022 \\
\hline Risky nutrition & $0.034 * *$ & 0.014 & 0.000 & 0.018 & $0.081 * * *$ & 0.022 \\
\hline Household size & $0.004^{*}$ & 0.002 & $0.006 *$ & 0.003 & 0.003 & 0.004 \\
\hline Primary & -0.010 & 0.024 & 0.025 & 0.029 & $-0.065 *$ & 0.040 \\
\hline Incomplete Secondary & -0.036 & 0.024 & -0.013 & 0.029 & $-0.077 * *$ & 0.039 \\
\hline Matric & $-0.054 * *$ & 0.027 & -0.030 & 0.034 & $-0.093 * *$ & 0.044 \\
\hline Post-secondary & $-0.159 * * *$ & 0.037 & $-0.114 * *$ & 0.048 & $-0.222 * * *$ & 0.055 \\
\hline Asset index & $-0.076 * * *$ & 0.011 & $-0.073 * * *$ & 0.014 & $-0.084 * * *$ & 0.017 \\
\hline Urban & 0.015 & 0.015 & 0.011 & 0.020 & 0.021 & 0.024 \\
\hline Coloured & $-0.106 * * *$ & 0.026 & $-0.137 * * *$ & 0.035 & -0.053 & 0.041 \\
\hline White & $-0.260 * * *$ & 0.027 & $-0.248 * * *$ & 0.037 & $-0.265 * * *$ & 0.040 \\
\hline Indian & $-0.261 * * *$ & 0.036 & $-0.291 * * *$ & 0.047 & $-0.210 * * *$ & 0.059 \\
\hline $\mathrm{N}$ & 7571 & & 4456 & & 3115 & \\
\hline $\mathrm{LR} \mathrm{Chi}^{2}$ & 1377.53 *** & & $808.25 * * *$ & & $580.86 * * *$ & \\
\hline
\end{tabular}

***, **** denotes statistically significant at 1\%, 5\% and $10 \%$ level of significance 
As for pain related conditions, arthritis, has a positive and statistically similar effect on men and women, while the effects of osteoporosis and epilepsy are not robust. For instance, epilepsy is significant for men and insignificant for women. The same applies to toothache as it increases women's propensity of being in poor health but is insignificant for men.

Findings for health related behaviour show that exposure to violence does not significantly influence both genders' chances of poor health. Smoking and risky nutrition do not have robust effects across the models; both are insignificant for women and for men they have positive and statistically significant effects. Participating in physical exercises is beneficial for both men and women as it reduces the chances of being in poor health. The reverse is the case for alcohol intake which increases both genders' chances of poor health.

Further, the results show that having some form of education decreases men's chances of being in poor health; effect increases with education levels. Apart from post-secondary education, other education levels do not significantly influence women's chances of being in poor health. Related to this, findings for the asset index exhibits a negative association with probability of being in poor health; implying that economic status matters for individuals' health. Finally, Table 4 reveals that other races have lower chances of reporting poor health than Africans (base category).

\section{Decomposition of the gender health gap}

Given that women have poor health status than men, we proceed to analyse sources of the observed gender health gap using decomposition analysis as in equation (3). The results are presented in Table 5.

Table 5: Decomposition of the gender differential in self-rated health status (\% points shown)

\begin{tabular}{l|c}
\hline Fraction of women who reported fair/poor health & 0.627 \\
\hline Fraction of men who reported fair/poor health & 0.538 \\
\hline Difference (women-men) & 0.089 \\
\hline Decomposition of difference & 0.021 \\
\hline $\begin{array}{l}\text { Severity effect } \\
\text { contribution to total gap: } 24.12 \%\end{array}$ & 0.068 \\
\hline $\begin{array}{l}\text { Prevalence effect } \\
\text { contribution to total gap: } 77.25 \%\end{array}$ & -0.001 \\
\hline Residual difference & \\
\hline
\end{tabular}

According to Table 5, the predicted proportion of women with poor/fair health is $62.7 \%$ while it is $53.8 \%$ for men. The total difference between men and women's predicted self-rated health status (Hgap) is 8.9\% points. A decomposition of Hgap into prevalence, severity and residual effects, based on equation (3), shows that 
$77.2 \%$ of the gap is due to prevalence effect, and $24 \%$ by the severity effect. To check the robustness of these results, we use an alternative health measure i.e. health service utilisation. Findings for probit models of health service utilisation are presented in Table A. 2 in the Appendix. They show that women are more likely to utilise health services relative to men. Assuming that most individuals utilise health services for treatment, it can be argued that women experience worse health status than men. This can be true given that health conditions are positively correlated with health service utilisation. Table 6 presents the decomposition of the gender gap in health service utilisation.

Table 6: Decomposition of the gender differential in health service utilisation (\% points shown)

\begin{tabular}{l|c}
\hline Fraction of women who utilised health care services & 0.401 \\
\hline Fraction of men who utilised health care services & 0.286 \\
\hline Difference (women-men) & 0.115 \\
\hline Decomposition of difference & \\
\hline $\begin{array}{l}\text { Severity effect } \\
\text { contribution to total gap: } \quad-8.76 \%\end{array}$ & -0.010 \\
\hline $\begin{array}{l}\text { Prevalence effect } \\
\text { contribution to total gap: } 79.58 \%\end{array}$ & 0.091 \\
\hline Residual difference & 0.034 \\
\hline
\end{tabular}

The predicted fraction of women who utilised health facilities is $40.1 \%$, the corresponding figure for men is $28.6 \%$. This implies that the total gap between men and women's predicted probabilities (Hgap) is $11.5 \%$ points. The decomposition shows that $79.5 \%$ of Hgap is due to the prevalence effect. An important finding from this robustness check is that the Hgap uncovered using HSU is somewhat larger than that for SRH while the decomposition results lead to the same conclusion. The consistency of our results for both measures of health is reassuring that our results are robust.

\section{$5 \quad$ Discussion of findings}

Our findings show that women are more likely to experience poor health relative to men. Regardless of the measure of health used, the bulk of the female-male health gap is explained by differences in the distribution of health conditions rather than by differences in the seriousness of the conditions. Put differently, this means women's inferior self-reported health status arises because they experience a higher prevalence of diseases than men, not because of the severity of the diseases that they face. This result is in line with Case and Paxson (2005) who also find that the gap in self-rated health is largely explained by the prevalence effect. These results imply that if men and women had the same distribution of conditions, the gender gap would be reduced by approximately $77.2 \%$ to $79.5 \%$. Contrary to the common view that the health gap 
closes with age, we find that the gap exhibits little variation across age groups and it persists in old age. South African women appear to be disadvantaged throughout their life-cycle compared to men.

The results for the occurrence of health conditions are not clear-cut. Previous studies suggest that women suffer more from non-fatal conditions while men suffer more from life-threatening conditions. Our findings reveal that both men and women experience fatal conditions, although their nature is different. Women experience higher rates of pain, and are more likely to suffer from circulatory conditions relative to men. Overall for respiratory conditions the results are mixed. However, men suffer more from tuberculosis while women are more likely to be asthmatic. This is in line with MacIntyre et al. (1996) who disagreed with the "near universal" picture of female excess morbidity. Regarding health care utilisation, we note that both men and women have health needs, however women need and use the health care system more often than men. Women's reproductive health care needs are part of the reason for increased use, but more women than men also suffer from one or more chronic conditions that could be prevented and also require ongoing care when it occurs, such as arthritis, epilepsy, and osteoporosis. As such, economic development may be compromised if the gender health gap is not addressed. It may affect welfare at the individual level, household and the economy at large, given the important role played by women at home while contributing economically in the work place. Female headed households and female breadwinners are on an increase in South Africa. Women also contribute to total production in the economy, given the increase in their participation in the labour market.

\section{Conclusion}

This paper investigates whether South African women experience worse health conditions than their male counterparts. This is topical given the rising inequality in South Africa - which is widely documented in terms of income and access to social resources like education and healthcare, among others. Evidence on inequality along the health dimension is limited yet it is also important for economic development. The findings show that women are more likely to experience poor health than men. We find that the gender health gap is between $8 \%$ and $11.5 \%$ which is quite modest. Given the fact that women typically seek care in primary care settings at different stages of life, this study underlies the importance of comprehensive standard of health care that includes health care screening, counselling (counselling on obesity prevention and smoking cessation), early diagnosis, health education and early intervention health care services that provide appropriate quality care for identified risk factors and health conditions in a health system based on the principles of social solidarity, equity and fairness (DoH, 2013).

The current overhauling of the health care system in South Africa gives a window of opportunity to establish a comprehensive standard of health for South Africans, 
especially women. The proposed reform, including the introduction of the NHI, has emphasised and centred the current revamping on PHC. As laid out in the ANC's discussion document: "At the core of revitalising and strengthening of the South African health system is a primary health care approach that seeks to improve access to quality health services as the first point of entry to the health system" (ANC General Council 2010, pp. 33). The discussion document envisions a renewed health system in which primary health care facilities provide $80 \%$ of care, with higher levels accessible only by referral. As such, the primary health care will be expanded to include extensive community- and home-based services. Hopefully, this will redress the health disparities and the gaps in overall provision of health care at all age groups given that the health gap is almost uniformly distributed across age groups in South Africa according to our results.

\section{References}

African National Congress (ANC). 2010. Additional Discussion Documents: National Health Insurance: 3-48, [online] URL: www.anc.org.za/docs/discus/2010/aditionalo.

Arber, S. \& Cooper, H. 1999. 'Gender differences in health in later life: The new paradox?', Social Science and Medicine, 48:61-76.

Ardington, C. \& Case, A. 2009. Health: Analysis of the NIDS wave 1 dataset, Southern African Labour \& Development Research Unit, Discussion Paper no. 2.

Blinder, A.S. 1973. 'Wage discrimination: reduced form and structural estimates', Journal of Human Resources, 8:436-455.

Bloom, D. \& Canning, D. 2000. 'The health and wealth of nations', Science 287:1207-09.

Bor, J., Rosen, S., Chimbindi, N., Haber, N., Herbst, K., Mutevedzi, T.,Tanper, F., Pillay, D. \& Bärnighausen, T. 2015. 'Mass HIV treatment and sex disparities in life expectancy: Demographic surveillance in rural South Africa', PLoS Medicine, 12(11).

Bradshaw, D. \& Steyn K. eds. 2001. Poverty and chronic diseases in South Africa. Cape Town: South African Medical Research Council.

Bradshaw D, Groenewald P, Laubscher R, Nannan N, Nojilana B, Norman R, Pieterse D and Schneider M (2003). Initial Burden of Disease Estimates for South Africa, 2000. Cape Town: South African Medical Research Council.

Case, A. \& Paxson, C. 2005. 'Sex differences in morbidity and mortality', Demography, 42(2):189214.

Cleveland, W.S. 1979. 'Robust locally weighted regression and smoothing scatterplots', Journal of the American Statistical Association 74:829-836.

Crimmins, E.M., Kim, J.K. \& Sole'-Auro', A. 2010. 'Gender differences in health: results from SHARE, ELSA and HRS', European Journal of Public Health, 21(1):81-91. 
Department of Health. 2010. Re-engineering primary health care in South Africa: Discussion document. Pretoria: Department of Health.

Department of Health. 2011. National health insurance in South Africa, Policy paper.

Department of Health. 2013. National health insurance: The first eighteen months. [online] URL: www.doh.gov.za/docs/policy/2013/NHI_1st_eighteen_month.pdf.

Doolan, K., Ehrlich R. \& Myer, L. 2007. 'Experience of violence and socioeconomic position in South Africa: A national study’, Plos One, 2:e1290.

Econex. 2009. South Africa's burden of disease. National Health Insurance (NHI), Note 2.

Even, W.E. \& Macpherson, D.A. 1990. 'Plant size and the decline of unionism', Economics Letters, 32:393-398.

Even, W.E. \& Macpherson, D.A. 1993. 'The decline of private-sector unionism and the gender wage gap', Journal of Human Resources, Spring: 279-296.

Fairlie, R.W. 2005. 'An extension of the blinder-oaxaca decomposition technique to logit and probit models', Journal of Economic and Social Measurement, 30:305-316.

Guralnik, J. M., Andrea Z., LaCroix, D.F., Everett \& Kovar, M.G. 1989. Aging in the eighties: The prevalence of comorbidity and its association with disability. Advance Data from Vital and Health Statistics 170. Hyattsville, MD: National Centre for Health Statistics.

Harling, G., Ehrlich, R. \& Myer, L. 2008. 'The social epidemiology of tuberculosis in South Africa: A multilevel analysis’, Social Science \& Medicine 2008(66):492-505.

Harris, B., Goudge, J., Ataguba, J.E., McIntyre, D., Nxumalo, N., Jikwana, S. \& Chersich, M. 2011. 'Inequities in access to health care in South Africa', Journal of Public Health Policy, 32:S102S123.

Hunt, K. 2002. 'A generation apart? Gender-related experiences and health in women in early and late mid-life', Social Science and Medicine 54:663-676.

Hunt, K. \& Annandale, E. 1999. 'Relocating gender and morbidity: examining men's and women's health in contemporary western societies: Introduction to special issue on gender and health', Social Science \& Medicine, 48(1):1-5.

International Monetary Fund. 2012. 'Empowering women is smart economics', Finance and Development, 49(1).

Institute for health metrics and evaluation. 2013. GBD country report South Africa. [online URL:http://www.healthmetricsandevaluation.org/sites/default/files/countryprofiles/GBD\%20Country\%20Report\%20-\%20South\%20Africa.pdf.

Jevon, P. 2012. Agina and heart attack - the facts. Oxford University Press.

Lahelma, E. \& Rahkonen, O. 1997. 'Health inequalities in modern societies and beyond', Social Science and Medicine, 44:721-910. 
Leinonen, R., Heikkinen, E. \& Jylha, M. 1997. 'Self-rated health and self-assessed change in health in elderly men and women-a five-year longitudinal study', Social Science and Medicine 46(45):591-97.

Lubitz, J., Cai, L., Kramarow, E. \& Lentzner, H. 2003. 'Health, life expectancy, and health care spending among the elderly', The New England Journal of Medicine, 349(11):1048-55.

MacIntyre, S., Hunt, K. \& Sweeting. H. 1996. 'Gender differences in health: Are things really as simple as they seem?', Social Science and Medicine, 42: 617-24.

McDonough, P. \& Walters, V. 2001. 'Gender and health: Reassessing patterns and explanations', Social Science and Medicine, 52:547-559.

Merrill, S.S., Seeman, T.E., Kasl, S.V. \& Berkman, L.F. 1997. 'Gender differences in the comparison of self-reported disability and performance measures', Journal of Gerontology: Medical Sciences,52A(1):M19-M26.

Molarius, A. \& Janson. S. 2002. 'Self-rated health, chronic diseases, and symptoms among middleaged and elderly men and women', Journal of Clinical Epidemiology, 55:364-70.

Myer L, Stein, D., Grimsrud, A., Seedat, S. \& Williams, D. 2008. 'Social determinants of psychological distress in a nationally-representative sample of South African adults', Social Science \& Medicine, 66:1828-1840.

Nathanson, C. 1975. 'Illness and the feminine role: A theoretical review', Social Science and Medicine, 9:57-62.

Nathanson, C. 1977. 'Sex, illness and medical care: A review of data, theory and method', Social Science and Medicine 11:13-25.

Okojie, C.E.E. 1994. 'Gender inequalities of health in the third world', Social Science and Medicine, 39(9): 1237-1247.

Oaxaca, R. 1973. 'Male-female wage differentials in urban labor markets', International Economic Review, 14:693-709.

Peacock, D. \& Levack, A. 2004. 'The men as partners program in South Africa: Reaching men to end gender-based violence and promote sexual and reproductive health', International Journal of Men's Health, 3(3).

Schaay, N., Sanders, D., Kruger, V. \& Olver, C. 2011. Overview of health sector reforms in South Africa. DFID Human Development Resource Centre.

Scully, P. 1995. 'Rape, race, and colonial culture: The sexual politics of identity in the nineteenthcentury cape colony, South Africa', The American Historical Review, 100(92):335-59.

Shisana, O., Rihele, T., Simbayi, L.C., Zuma, K., Jooster, S., Zungu, N., Labadarios, D. \& Onoya, D. 2014. South African national HIV prevalence, incidence and behaviour Survey 2012. Cape Town, HSRC Press. 
South African Medical Research Council. 2003. South Africa demographic and health survey 2003. [online] URL:http://www.mrc.ac.za/bod/sadhs.htm.

Spiers, N., Jagger, C., Clarke, M. \& Arthur, A. 2003. 'Are gender differences in the relationship between self-rated health and mortality enduring? Results from three birth cohorts in Melton Mowbray, United Kingdom', Gerontologist, 43:406-11.

Tischler, H.L. 2013. Introduction to sociology. $11^{\text {th }}$ edition Cengage Advantage Books, USA.

The Lancet. 2009. Health in South Africa, an executive summary for the Lancet series.

Verbrugge, L. 1979a. 'Females and illness: Recent trends in sex differences in the United States', Journal of Health and Social Behaviour, 17:387-403.

Verbrugge, L.M. 1985. 'Gender and health: An update on hypotheses and evidence', Journal of Health and Social Behaviour 26:156-82.

Verbrugge, L.M. 1989. 'The twain meet: Empirical explanations of sex differences in health and mortality', Journal of Health and Social Behaviour, 30(September):282-304.

Wilkie, J. \& Young, A. 2009. 'Why health matters for economic performance', Economic, 2009:57.-72.

World Health Organisation. 2012. World health statistics 2012. WHO Press. World Health Organisation, Geneva, Switzerland.

World Health Organisation. 2003. Gender and tuberculosis. WHO Press. World Health Organisation, Geneva, Switzerland.

Yin, S. 2007. Gender disparities in health and mortality. Washington, DC: Population Reference Bureau (November).

Yun, M-S. 2004. 'Decomposing differences in the first moment', Economics Letters 82:275-280.

Zeida, R.K. \& Lackan, N. 2008. 'Ethnic disparities in access to care in post-apartheid South Africa', American Journal of Public Health, 98(12):2272 - 2277.

\section{Appendix A}

\section{Table A1: Description of variables used in the study}

\begin{tabular}{l|l}
\hline Variable & Description \\
\hline SRH-dependent variable & Dummy for self-related health: 1 if poor or average, 0 if good or excellent \\
\hline HSU & Dummy: 1 if used healthcare services in past month, 0 otherwise \\
\hline Female & Gender dummy: 1 if Female, 0 otherwise \\
\hline Age dummies & $\begin{array}{l}\text { Dummy variables for individuals' age 15-24 years, 25-34 years, 35-44 } \\
\text { years, 45-54 years, 55-64 years, and 65 years and above }\end{array}$ \\
\hline Provincial Dummies & $\begin{array}{l}\text { Dummy variables for provincial location Western Cape, Eastern Cape, } \\
\text { Northern Cape, Free State, North West, Mpumalanga, Gauteng, and } \\
\text { Limpopo }\end{array}$ \\
\hline Urban & Dummy variable: 1 if an individual resides in an urban area, 0 Otherwise \\
\hline
\end{tabular}




\begin{tabular}{|c|c|}
\hline Household size & Number of people living in the same household \\
\hline No schooling & Dummy variable: 1 if an individual has 0 years of education, 0 otherwise \\
\hline Primary & $\begin{array}{l}\text { Dummy variable: } 1 \text { if an individual's education is in the range grade } 1-7,0 \\
\text { otherwise }\end{array}$ \\
\hline Incomplete Secondary & $\begin{array}{l}\text { Dummy variable: } 1 \text { if an individual's education is in the range form 1-4, } 0 \\
\text { otherwise }\end{array}$ \\
\hline $\begin{array}{l}\text { Matric/complete } \\
\text { Secondary }\end{array}$ & $\begin{array}{l}\text { Dummy variable: } 1 \text { if an individual completed form } 5 \text { or incomplete further } \\
\text { studies, } 0 \text { otherwise }\end{array}$ \\
\hline Post-Secondary & $\begin{array}{l}\text { Dummy variable: } 1 \text { if an individual's education is diploma or degree, } 0 \\
\text { otherwise }\end{array}$ \\
\hline Asset Index & $\begin{array}{l}\text { An index for ownership of a radio, a television, a computer, a refrigerator, } \\
\text { telephone/cellphone, a bicycle, a car, a donkey or cattle- derived using } \\
\text { Principal components Analysis }\end{array}$ \\
\hline African & Dummy variable: 1 if an individual's race is African, 0 otherwise \\
\hline Coloured & Dummy variable: 1 if an individual's race is Coloured, 0 otherwise \\
\hline Indian & Dummy variable: 1 if an individual's race is Indian, 0 otherwise \\
\hline White & Dummy variable: 1 if an individual's race is White, 0 otherwise \\
\hline Blood Pressure & $\begin{array}{l}\text { Dummy variable: } 1 \text { if an individual suffered from Blood Pressure, } 0 \\
\text { otherwise }\end{array}$ \\
\hline Heart Attack & Dummy variable: 1 if an individual had a Heart Attack, 0 otherwise \\
\hline Stroke & Dummy variable: 1 if an individual had a Stroke, 0 otherwise \\
\hline Cholesterol & Dummy variable: 1 if an individual had high Cholesterol, 0 otherwise \\
\hline Diabetes & Dummy variable: 1 if an individual had Diabetes, 0 otherwise \\
\hline Bronchitis & Dummy variable: 1 if an individual had Bronchitis/Emphysema, 0 otherwise \\
\hline Asthma & Dummy variable: 1 if an individual had Asthma , 0 otherwise \\
\hline Athritis & Dummy variable: 1 if an individual had Athritis, 0 otherwise \\
\hline Osteoporosis & Dummy variable: 1 if an individual had Osteoporosis, 0 otherwise \\
\hline Epilepsy & Dummy variable: 1 if an individual had Epilepsy, 0 otherwise \\
\hline Tuberculosis & Dummy variable: 1 if an individual had Tuberculosis, 0 otherwise \\
\hline Toothache & $\begin{array}{l}\text { Dummy variable: } 1 \text { if an individual had pain in mouth or teeth in past } 6 \\
\text { months, } 0 \text { otherwise }\end{array}$ \\
\hline Violence & $\begin{array}{l}\text { Dummy variable: } 1 \text { if an individual had been physically attacked in past } 12 \\
\text { months, } 0 \text { otherwise }\end{array}$ \\
\hline Pain & $\begin{array}{l}\text { Dummy variable: } 1 \text { if an individual had Arthritis/Osteoporosis/Epilepsy, } 0 \\
\text { otherwise }\end{array}$ \\
\hline Respiratory Conditions & $\begin{array}{l}\text { Dummy variable: } 1 \text { if an individual had Bronchitis/Tuberculosis/Asthma, } 0 \\
\text { otherwise }\end{array}$ \\
\hline Circulatory Conditions & $\begin{array}{l}\text { Dummy variable: } 1 \text { if an individual had Blood pressure/had a stroke/ had a } \\
\text { heart attack/ had cholesterol problems/ had diabetes, } 0 \text { otherwise }\end{array}$ \\
\hline Exercise & $\begin{array}{l}\text { Dummy variable: } 1 \text { if an individual does non-work related-leisure time } \\
\text { physical activity for at least } 10 \text { minutes }\end{array}$ \\
\hline Smoker & $\begin{array}{l}\text { Dummy variable: } 1 \text { if an individual currently smokes any tobacco products, } 0 \\
\text { otherwise }\end{array}$ \\
\hline Drinker & $\begin{array}{l}\text { Dummy variable: } 1 \text { if an individual should cut down on drinking/ is criticised } \\
\text { for drinking/ feels bad about the drinking, } 0 \text { otherwise }\end{array}$ \\
\hline Risky nutrition & $\begin{array}{l}\text { Dummy variable: } 1 \text { if an individual eats the following daily: fried foods, } \\
\text { chips, processed meat, very salty foods, } 0 \text { otherwise }\end{array}$ \\
\hline Underweight & Dummy variable: 1 if Body mass index $<=18.4$ \\
\hline Healthy weight & Dummy variable: 1 if Body mass index $>18.4 \& b m i<25$ \\
\hline Overweight & Dummy variable: 1 if Body mass index $>25 \&$ bmi $<29.9$ \\
\hline Obese & Dummy variable: 1 if Body mass index $>=30$ \\
\hline
\end{tabular}


Table A2: Results for probit models of health care utilisation by gender

\begin{tabular}{|c|c|c|c|c|c|c|}
\hline & Full model & & Women & & Men & \\
\hline Variable & Mean/Prop & Std. Err. & Mean/Prop & Std. Err. & Mean/Prop & Std. Err. \\
\hline Female & $0.086 * * *$ & 0.013 & & & & \\
\hline $25-34$ years & $0.096 * * *$ & 0.018 & $0.071 * * *$ & 0.024 & $0.126 * * *$ & 0.027 \\
\hline $35-44$ years & $0.081 * * *$ & 0.019 & $0.062 * *$ & 0.025 & $0.106 * * *$ & 0.029 \\
\hline $45-54$ years & $0.109 * * *$ & 0.021 & $0.083^{* * * *}$ & 0.028 & $0.136^{* * * *}$ & 0.033 \\
\hline 55-64 years & $0.137 * * *$ & 0.026 & $0.114 * * *$ & 0.034 & $0.158 * * *$ & 0.039 \\
\hline $65+$ years & $0.188 * * *$ & 0.030 & $0.139 * * *$ & 0.040 & $0.248 * * *$ & 0.047 \\
\hline Blood Pressure & $0.238 * * *$ & 0.019 & $0.242 * * *$ & 0.022 & $0.237 * * *$ & 0.035 \\
\hline Heart attack & $0.098 * * *$ & 0.034 & $0.091 * *$ & 0.042 & $0.108^{*}$ & 0.057 \\
\hline Stroke & $0.105^{*}$ & 0.063 & 0.121 & 0.085 & 0.071 & 0.089 \\
\hline Cholesterol & $0.123 * * *$ & 0.046 & $0.138 * * *$ & 0.061 & 0.086 & 0.068 \\
\hline Diabetes & $0.169 * * *$ & 0.036 & $0.181 * * *$ & 0.045 & $0.156 * * *$ & 0.059 \\
\hline Bronchitis & $0.143 * * *$ & 0.043 & $0.107 * *$ & 0.054 & $0.190 * * *$ & 0.072 \\
\hline Asthma & $0.122 * * *$ & 0.033 & $0.179 * * *$ & 0.041 & 0.032 & 0.051 \\
\hline Arthritis & $0.160 * * *$ & 0.027 & $0.170 * * *$ & 0.033 & $0.141 * * *$ & 0.046 \\
\hline Osteoporosis & 0.025 & 0.046 & 0.072 & 0.059 & -0.050 & 0.068 \\
\hline Epilepsy & $0.182 * * *$ & 0.053 & $0.209 * * *$ & 0.067 & $0.148^{*}$ & 0.082 \\
\hline Tuberculosis & $0.141 * * *$ & 0.039 & 0.088 & 0.056 & $0.182 * * *$ & 0.054 \\
\hline Toothache & $0.101 * * *$ & 0.016 & $0.091 * * *$ & 0.020 & $0.120 * * *$ & 0.024 \\
\hline Violence & $0.054 * *$ & 0.031 & 0.063 & 0.046 & 0.046 & 0.040 \\
\hline Exercises & -0.002 & 0.014 & -0.001 & 0.020 & -0.002 & 0.019 \\
\hline Smoker & -0.002 & 0.016 & 0.010 & 0.027 & -0.016 & 0.019 \\
\hline Drinker & -0.010 & 0.016 & 0.010 & 0.026 & -0.023 & 0.019 \\
\hline Risky nutrition & 0.005 & 0.014 & 0.001 & 0.019 & 0.009 & 0.020 \\
\hline Household size & 0.002 & 0.002 & 0.002 & 0.003 & 0.003 & 0.003 \\
\hline Primary & $0.046^{* *}$ & 0.022 & $0.060 * *$ & 0.028 & 0.025 & 0.033 \\
\hline $\begin{array}{l}\text { Incomplete } \\
\text { Secondary }\end{array}$ & -0.001 & 0.022 & 0.004 & 0.029 & -0.015 & 0.032 \\
\hline Matric & 0.017 & 0.025 & 0.026 & 0.034 & -0.003 & 0.037 \\
\hline Post-secondary & 0.011 & 0.034 & 0.024 & 0.046 & -0.011 & 0.048 \\
\hline Asset index & $0.019^{*}$ & 0.010 & 0.018 & 0.014 & 0.022 & 0.015 \\
\hline Urban & 0.000 & 0.015 & -0.006 & 0.020 & 0.004 & 0.021 \\
\hline Coloured & -0.037 & 0.024 & -0.018 & 0.033 & $-0.058 * * *$ & 0.032 \\
\hline White & 0.011 & 0.026 & -0.003 & 0.036 & 0.028 & 0.038 \\
\hline Indian & -0.016 & 0.034 & 0.003 & 0.046 & -0.035 & 0.048 \\
\hline $\mathrm{N}$ & 7571 & & 4456 & & 3115 & \\
\hline LR Chi $^{2}$ & $1116.22^{*} * *$ & & $636.69 * * *$ & & $402.50^{* * *}$ & \\
\hline
\end{tabular}

***,**,* denotes statistically significant at $1 \%, 5 \%$ and $10 \%$ level of significance 